\title{
Reanalysis of Gene Expression Profiles of CD4+ T Cells Treated with HIV-1 Latency Reversal Agents
}

\author{
Antonio Victor Campos Coelho ${ }^{1, *(\mathbb{C})}$, Ronald Rodrigues de Moura ${ }^{2}$ and Sergio Crovella ${ }^{2,3}$ (1) \\ 1 Federal University of Pernambuco, Avenida da Engenharia, Cidade Universitária, Recife 50670-901, Brazil \\ 2 Institute for Maternal and Child Health-IRCCS Burlo Garofolo, 34137 Trieste, Italy; \\ ronaldmoura1989@gmail.com (R.R.d.M.); crovelser@gmail.com (S.C.) \\ 3 Department of Medical, Surgical and Health Sciences, University of Trieste, 34127 Trieste, Italy \\ * Correspondence: avccbio@gmail.com; Tel.: +55-81-2126-8522
}

Received: 22 July 2020; Accepted: 21 September 2020; Published: 30 September 2020

\begin{abstract}
The human immunodeficiency virus (HIV-1) causes a progressive depletion of CD4+ T cells, hampering immune function. Current experimental strategies to fight the virus focus on the reactivation of latent HIV-1 in the viral reservoir to make the virus detectable by the immune system, by searching for latency reversal agents (LRAs). We hypothesize that if common molecular pathways elicited by the presence of LRAs are known, perhaps new, more efficient, "shock-and-kill" strategies can be found. Thus, the objective of the present study is to re-evaluate RNA-Seq assays to find differentially expressed genes (DEGs) during latency reversal via transcriptome analysis. We selected six studies (45 samples altogether: 16 negative controls and 29 LRA-treated CD4+ T cells) and 11 LRA strategies through a systematic search in Gene Expression Omnibus (GEO) and PubMed databases. The raw reads were trimmed, counted, and normalized. Next, we detected consistent DEGs in these independent experiments. AZD5582, romidepsin, and suberanilohydroxamic acid (SAHA) were the LRAs that modulated most genes. We detected 948 DEGs shared by those three LRAs. Gene ontology analysis and cross-referencing with other sources of the literature showed enrichment of cell activation, differentiation and signaling, especially mitogen-activated protein kinase (MAPK) and Rho-GTPases pathways.
\end{abstract}

Keywords: reservoir; shock-and-kill; antiretroviral therapy; RNA-Seq; transcriptomics

\section{Introduction}

The human immunodeficiency virus (HIV-1) is the causative agent of acquired immunodeficiency syndrome (AIDS), characterized by a chronic, progressive depletion of CD4+ T cells, hampering immune function and thus posing vulnerability to opportunistic infections [1-3]. Antiretroviral therapy (ART) is the standard treatment against human immunodeficiency virus type 1 (HIV-1). Since 1996, it has been saving millions of lives by inhibiting viral genome replication and protein maturation in those infected [4].

Unfortunately, ART does not cure definitively HIV-1 infection because this retrovirus integrates its genome on the cells it infects, setting up latent infection. Should ART treatment be discontinued, the virus is promptly reactivated, restarting production of viral particles and immune system destruction [5]. The major component of the latent viral reservoir are memory CD4+ $\mathrm{T}$ cells, which are capable of self-renewal and long-term survival [6]. It has been estimated that memory CD4+ T cells have a mean half-life of around 44 months. Because of this, it would take more than 70 years for the latent reservoir to disappear in an average person in viral suppression [7].

According to two impressive reports of a HIV-1 clinical cure of two men following allogeneic haemopoietic stem-cell transplantation [8,9], the pathway to a definite HIV-1 cure has been paved: the 
elimination of the latent viral reservoir. The current challenge is therefore the development of a less invasive method than bone marrow transplantation for the elimination of the said reservoir.

A strategy is the search for latency reversal agents (LRAs), which are molecules or compounds that are able to activate latent HIV-1 from its dormant state in the viral reservoir from an infected individual, with the purpose of gradually eliminating the viral reservoir, thus making the virus detectable by the immune system, a method nicknamed as "shock-and-kill" or "kick-and-kill". The investigated LRAs have generally targeted epigenetic pathways (such as histone deacetylase inhibitors - HDACi, such as vorinostat, also known as suberanilohydroxamic acid or SAHA, and valproic acid) and T cell receptor (TCR) agonists. A major problem of this effort is that LRAs generally fail to reverse latency in studies of cells from HIV-1-infected individuals [10].

We hypothesize that if the molecular pathways elicited by the presence of LRAs are known, perhaps it may help the design of new, more efficient, and safer, "shock-and-kill" strategies.

Transcriptional profiling via RNA sequencing (RNA-Seq) has been widely used over the last decade and has become the assay of choice to unravel the relationship between cellular function and phenotypes [11-13]. Thus, the objective of the present study is reevaluating RNA sequencing (RNA-Seq) assays deposited in public databases to find differentially expressed genes (DEGs) during latency reversal, aimed at unifying knowledge about pathways possibly involved in the action of LRAs on reservoirs from HIV-infected individuals.

\section{Materials and Methods}

\subsection{Study Search Strategies}

We searched for latency reversal RNA-Seq studies via Sequence Read Archive (SRA) [14] searching through Gene Expression Omnibus (GEO) database [15,16] and PubMed [17] databases. In SRA database, the following search string containing commonly used LRAs [18] was used: HIV-1 AND (latency OR latency reversal agent* OR latency reversing OR LRA* OR romidepsin OR panobinostat OR Q1 OR ingenol-3-angelate OR bryostatin-1 OR PMA OR ionomycin) AND homo sapiens [Organism]. This resulted in 676 abstracts. After filtering for "Expression profiling by high throughput sequencing" in Study type, we obtained 18 abstracts.

A similar search string: HIV-1 AND (OR romidepsin OR panobinostat OR Q1 OR ingenol-3-angelate OR bryostatin-1 OR PMA OR ionomycin) AND homo sapiens AND RNA-Seq, was used in PubMed database, resulting in 15 abstracts. The list of abstracts retrieved by the two strategies was downloaded and processed in a spreadsheet to remove duplicates and for further evaluation if they would be included in the study.

For inclusion in the reanalysis, we used the following criteria: whole transcriptome studies; experiments carried out in CD4+ T cells and availability of the raw data (fastq files) for each sample. The search was performed on 16 March 2020.

\subsection{RNA-Seq Data Collection, Processing, and Statistical Analyses}

Raw fastq files were downloaded using $S R A d b$ package [19] for R software v. 3.6 .1 [20] or via Phil Ewel's SRA-Explorer online tool (http://sra-explorer.info/). Only sequencing reads from samples meeting the following criteria were downloaded: LRA-treated and negative controls (not treated with LRA or vehicle-treated, such as DMSO-treated cells). Exclusion criteria: mock-infected samples, single cell samples, positive controls samples (such as CD3+CD28+IL-2 stimulation to induce global CD4+ T cell activation, which is toxic and not clinically relevant). To simplify analyses, we downloaded the runs for the last time point only in case the original study had time-repeated design.

The reads were re-processed using Trimmomatic software v. 0.39 [21] to trim Illumina adapters and to exclude reads counting less than 25 bases. Then, the remaining reads were mapped on the National Center for Biotechnology (NCBI) human GRCh38 reference genome and sorted by coordinates using STAR aligner [22]. Binary Alignment Map reads (BAM files) were imported into R software and 
processed with Rsubread package [23], whose featureCounts function mapped sequencing reads to genomic features using an in-built human GRCh38 genome annotation (28.395 genes), quantifying raw expression levels per gene per sample, producing a gene count table for each sample. All subsequent analyses were made with R software v. 3.6.1 [20].

The counts from technical replicas and CD4+ T cell subpopulations were collapsed into single count per unique sample, representing gene expression in CD4+ T cell pools. Then, sample counts were normalized via trimmed mean of M values (TMM) method in a study-by-study basis, allowing differential gene expression analysis by negative binomial generalized linear models with per gene, per LRA testing by quasi-likelihood F-test, alongside calculation of log2-transformed expression fold changes for each gene (through comparison of LRA-treated samples with non-LRA-treated samples) with the help of edgeR package [24].

Finally, $\log 2$-transformed fold changes mentioned above were matched with their respective pooled, false discovery rate (FDR) adjusted $p$-values. The genes with both $\mid \log 2$ (Fold-Change) $\mid>1$ and adjusted $p$-value $<0.05$ via were considered to be statistically significant DEGs.

Gene names (symbols) were derived from gene ids with annotate [25] and org.Hs.eg.db [26] packages.

\subsection{Cross-Referencing and Set Analysis of DEGs}

We cross-referenced the differential expression re-analyses results with the observations of other studies from the literature investigating HIV-1 infection and replication [27-30] and two databases: HIV-1 Human Interaction Database [31-33] and RNAcentral, a database of non-coding RNA [34] using NCBI RefSeq [35] gene symbols as external identifiers. Briefly, the tables obtained from the differential expression analyses and curated tables from the two databases were imported into a local PostgreSQL relational database. The tables were linked to reveal which genes were activated by each LRA and more importantly, which genes were modulated by several LRAs, and to assess if said genes were already identified by the literature, so we could identify genes consistently involved in HIV-1 latency reversal.

The VennDiagram [36] package was used for evaluation of intersection among the selected results, revealing the number of commonly modulated genes by different LRAs.

To assess whether our results agreed with original sources investigated, we performed simulations to determine an expected overlap number if each set were truly independent (created by pure chance). The expected overlap number was determined by producing empirical simulations using "mock genes", a list of random but unique strings to represent gene symbols with the ids package of $\mathrm{R}$ software [37].

First, we produced a list of 28395 unique random strings to represent our annotated human genome. From this list, we randomly sampled two independent sets. The first one contained $R$ elements, representing our list of genes following differential expression analysis. The second one contained $O$ elements, where $O$ was the size of the original genes list reported by each source. The process of formation of these two sets was repeated 10,000 times. Each time, the two sets were different from the previous ones, and the number of overlapping genes (intersection) was calculated.

Thus, we obtained 10000 intersection values. The median of these values was considered to be the expected number. Therefore, the binomial distribution was used to test the observed intersection number with this expected number via one-sided tests under the null hypothesis that the intersection of the original source with the reanalysis list is equal or less than expected by chance. If $p$-value $<0.05$, we would reject the null hypothesis and assume that our results had a higher concordance with the source than expected by chance.

\subsection{Gene Ontology and Reactome Pathway Enrichment Analysis}

After obtaining the intersection list as described above, we performed a gene ontology (GO) enrichment analysis through over-representation analyses with the goana function of the limma package [38]. Then, the $\mathrm{p}$-values were FDR-adjusted also with $\mathrm{R}$ software. The genes were ranked from the lowest to highest below level of significance $\alpha=0.05$. 
Additionally, we conducted pathway analysis, based on the REACTOME database, of the statistically significant DEGs using the ReactomePA package [39]. Each pathway $p$-value was FDR-adjusted with $p$-values $<0.05$ being considered significant.

\section{Results}

The search strategy resulted in 33 abstracts. Following duplicates removal, abstracts were screened, producing a shortlist of ten studies for further review to check if they met the inclusion criteria mentioned previously. From those, six were reanalyzed, being five studies with published reports [40-44]. We could not ascertain if the remaining project, submitted publicly by the contributor Vallejo-Gracia on April 2019, which was retrieved from the search through GEO database has already been published. We assumed they fit into our inclusion criteria, so we included this project in the reanalysis.

The other four were excluded; three were conducted in uninfected cells [45-47] and one did not provide raw sequencing reads in public databases [48].

The first study, from Mohammadi et al. (GSE95297) [40] recruited HIV-1-infected individuals with controlled viremia (plasma viral load, $\mathrm{pVL}<20$ copies $/ \mathrm{mL}$ ), isolated and pooled their resting CD4+ T cells and treated with disulfiram, interleukin (IL)-7 or SAHA. Since the authors suspended the drugs in dimethyl sulfoxyde (DMSO), the control sample was treated with DMSO only, thus totaling four samples selected: three treated samples and one control sample.

The second study, from Golumbeanu et al. (GSE111727) [41] recruited blood donors and HIV-1 patients included in the Swiss HIV-1 Cohort Study. CD4+ T cells were purified from uninfected blood donors and activated through TCR stimulation. Three days post-activation, cells were transduced with a recombinant HIV-1 vector. Then, cells were allowed to revert to a resting phenotype by long-term culture. Finally, for reactivation, cells were incubated with SAHA for $24 \mathrm{~h}$. Control cells were left untreated. This study contributed with two samples: one untreated and one SAHA-treated.

The third study, from Beliakova-Bethell et al. (GSE114883) [42] used samples of primary CD4+ $\mathrm{T}$ cells from HIV-1-negative blood donors which were then infected through a laboratory bystander infection model [49]. This study included 12 samples from four donors, being four controls and eight LRA-treated (one control sample per donor-treated with DMSO only and two treated samples per donor-with SAHA or romidepsin).

The fourth study, from Kulpa et al. (GSE94150) [43] recruited virologically suppressed HIV-1-infected individuals, isolated their CD4+ T cells and subjected them to four conditions: no stimulus (control cells), stimulation for $24 \mathrm{~h}$ with: phorbol 12-myristate 13-acetate (PMA) plus ionomycin; IL-15 or bryostatin. It is important to highlight that the authors sequenced three CD4+ T cells subpopulations separately (effector memory, transient memory, and central memory) for each donor. For our analysis, however, we pooled together the sequencing reads from those three groups, to approximate a whole CD4+ sample from each donor. This study contributed with nine samples (three controls, one from each donor, three IL-15-treated, and three bryostatin-treated, both treatments also one sample from each donor).

The fifth study, by Vallejo-Gracia et al. (GSE129522) (unpublished), seems to include three donors, which their CD4+ T cells were treated with the LRA AS1842856, a small molecule that acts as a FOXO1 transcription factor inhibitor [50], or received only DMSO as control for at most $48 \mathrm{~h}$, totaling, therefore, six samples.

The sixth study, by Nixon et al. (GSE142774) [44] included three virologically suppressed HIV-1-infected donors. Cells from each patient were treated with DMSO (control), AZD5582, an antagonist of inhibitor of apoptosis proteins (IAPs) [51], or ingenol B, a protein kinase C (PKC) agonist [52] for at most $24 \mathrm{~h}$, resulting in 12 samples (one control and two LRA-treated samples per donor). 
In summary, we considered nine strategies in our reanalysis: disulfiram, IL-7, SAHA, romidepsin, IL-15, bryostatin, AS1842856, AZD5582 and ingenol B. Overall, 45 unique samples were selected for inclusion in the reanalysis, being 29 treated with any LRA and 16 were (negative) controls. Table 1 summarizes the studies' information and main results. Table S1 lists the selected individual samples alongside their respective sequencing reads ids from SRA database.

Table 1. Summary of studies included in the reanalysis of gene expression profiles of CD4+ T cells treated with HIV-1 latency reversal agents (LRA).

\begin{tabular}{|c|c|c|c|c|c|}
\hline Study & GSE id & LRA Used & $\begin{array}{l}\text { Selected } \\
\text { Samples }\end{array}$ & $\begin{array}{c}\text { Control:Treated } \\
\text { Ratio }\end{array}$ & Main Results \\
\hline $\begin{array}{c}\text { Mohammadi et al. (2014) } \\
\text { [40] }\end{array}$ & GSE95297 & $\begin{array}{l}\text { disulfiram, } \\
\text { IL-7, SAHA }\end{array}$ & 4 & 1:3 & $\begin{array}{l}\text { Use of SAHA, disulfiram or IL-7 do not } \\
\text { result in efficient viral protein } \\
\text { expression upon reactivation. } \\
\text { The authors suggest that } \\
\text { post-transcriptional blocks also } \\
\text { contribute to latency. }\end{array}$ \\
\hline $\begin{array}{c}\text { Golumbeanu et al. (2018) } \\
\text { [41] }\end{array}$ & GSE111727 & SAHA & 2 & 1:1 & $\begin{array}{l}\text { Latently infected cells respond to virus } \\
\text { reactivation in a heterogeneous manner. } \\
\text { The authors identified a 134-gene } \\
\text { cluster in cells most susceptible to } \\
\text { induction. }\end{array}$ \\
\hline $\begin{array}{l}\text { Beliakova-Bethell et al. } \\
\text { (2019) [42] }\end{array}$ & GSE114883 & $\begin{array}{l}\text { romidepsin } \\
\text { or SAHA }\end{array}$ & 12 & $1: 2$ & $\begin{array}{c}\text { The authors identified genes modulated } \\
\text { by SAHA and romidepsin that were } \\
\text { implicated as HIV transcriptional } \\
\text { regulators. }\end{array}$ \\
\hline Kulpa et al. (2019) [43] & GSE94150 & $\begin{array}{l}\text { Bryostatin } \\
\text { or IL-15 }\end{array}$ & 9 & $1: 2$ & $\begin{array}{l}\text { The authors conclude that HIV gene } \\
\text { expression is associated with } \\
\text { up-regulation of CD4+ T cell } \\
\text { differentiation, acquisition of effector } \\
\text { function, and cell cycle entry, being } \\
\text { effector memory cells the most } \\
\text { inducible cells of the viral reservoir. }\end{array}$ \\
\hline $\begin{array}{l}\text { Vallejo-Gracia et al. } \\
\text { (2019, unpublished) }\end{array}$ & GSE129522 & AS1842856 & 6 & 1:1 & Not available. \\
\hline Nixon et al. (2020) [44] & GSE142774 & $\begin{array}{l}\text { AZD5582 or } \\
\text { Ingenol B }\end{array}$ & 12 & $1: 2$ & $\begin{array}{l}\text { The authors suggest that activation of } \\
\text { the non-canonical NF-kB signaling } \\
\text { pathway by AZD5582 results in the } \\
\text { reactivation of HIV in animal models } \\
\text { with little toxicity. }\end{array}$ \\
\hline
\end{tabular}

Overall, there were 15953 statistically significant LRA-differentially expressed gene pairs, corresponding to 9494 unique genes. AS1842856 and IL-15 stimulation did not significantly modulate genes. Table S2 contains this list of LRA-gene pairs, with their respective log2 (Fold-Change) and FDR-adjusted quasi-likelihood F-test $p$-value.

Among the remaining seven LRAs, three remarkedly modulated the most genes: romidepsin (5798 genes, 33.7\% of all expressed genes in the samples), followed by AZD5582 (4512, 30.0\%) and SAHA, $(3218,19.0 \%)$ also in the Beliakova-Bethell et al. [42] study samples. All three were associated with the differential expression of more than $10 \%$ of all expressed genes in the sample, whereas all others LRAs modulated much less genes (disulfiram: 473, 2.8\%; ingenol B: 443, 3.0\%; Il-7: 199, 1.2\% and bryostatin: 20, $0.2 \%$; results summarized in Table 2 ). 
Table 2. Summarized results of the differential expression reanalysis.

\begin{tabular}{|c|c|c|c|c|c|c|c|}
\hline Reference & LRA & DEGs $^{a}$ & $\begin{array}{c}\text { Up-Regulated } \\
\text { Genes }\end{array}$ & $\begin{array}{c}\text { Down-Regulated } \\
\text { Genes }\end{array}$ & $\begin{array}{c}\text { Total Expressed } \\
\text { Genes }\end{array}$ & $\begin{array}{c}\% \text { of DEGs } \\
\text { among } \\
\text { Expressed } \\
\text { Genes }\end{array}$ & $\begin{array}{c}\% \text { of DEGs } \\
\text { among Whole } \\
\text { Genome }^{c}\end{array}$ \\
\hline Beliakova-Bethell et al. 2019 [42] & romidepsin & 5798 & 2934 & 2864 & 17223 & 33.7 & 20.4 \\
\hline Nixon et al. 2020 [44] & AZD5582 & 4512 & 1996 & 2516 & 15063 & 30.0 & 15.9 \\
\hline Beliakova-Bethell et al. 2019 [42] & & 3218 & 1651 & 1567 & 16949 & 19.0 & 11.3 \\
\hline Mohammadi et al. 2014 [40] & $\mathrm{SAHA}^{\mathrm{b}}$ & 942 & 691 & 251 & 17160 & 5.5 & 3.3 \\
\hline Golumbeanu et al. 2018 [41] & & 348 & 191 & 157 & 15991 & 2.2 & 1.2 \\
\hline Mohammadi et al. 2014 [40] & disulfiram & 473 & 263 & 210 & 17002 & 2.8 & 1.7 \\
\hline Nixon et al. 2020 [44] & ingenol B & 443 & 292 & 151 & 14935 & 3.0 & 1.6 \\
\hline Mohammadi et al. 2014 [40] & IL-7 & 199 & 122 & 77 & 16503 & 1.2 & 0.7 \\
\hline Kulpa et al. 2019 [43] & bryostatin & 20 & 2 & 18 & 12511 & 0.2 & 0.1 \\
\hline Vallejo-Gracia et al. 2019, unpublished & AS1842856 & 0 & 0 & 0 & 16840 & 0.0 & 0.0 \\
\hline Kulpa et al. 2019 [43] & IL-15 & 0 & 0 & 0 & 12271 & 0.0 & 0.0 \\
\hline
\end{tabular}

a 9494 unique genes, ${ }^{\text {b }} 3922$ unique genes, c 28,395 annotated genes. 
There were a few genes shared by LRAs. Most genes (5105 among 9494, 53.8\%) were modulated by a single LRA only. Any combination of two, three and four LRAs shared 3089 (32.5\%), 1132 (11.9\%) and $152(1.6 \%)$ genes, respectively. Just 16 genes $(0.2 \%)$ where shared by any combination of five LRAs: ACE, AIRE, BAIAP3, C20orf197, CACNA1I, CR1, CXCR4, DTX4, FCGBP, GPA33, LOC105377746, NME2, PI16, SIRPG-AS1, TCF7 and TMIE. No gene was simultaneously activated by six or seven distinct LRAs (Table 3). Table S3 contains the list of 9494 unique genes differentially expressed during LRA stimulation, the DEG list from each study/LRA and the cross-referencing with the literature and databases. Table $\mathrm{S} 4$ contains the detailed distribution of how many genes were activated by number of HIV latency reversal agents.

Table 3. Distribution of how many genes were activated by number of HIV latency reversal agents ( $\mathrm{n}=7$ strategies).

\begin{tabular}{ccc}
\hline Number of LRAs & Unique Genes & Percentage \\
\hline 1 & 5105 & 53.8 \\
2 & 3089 & 32.5 \\
3 & 1132 & 11.9 \\
4 & 152 & 1.6 \\
5 & 16 & 0.2 \\
6 or 7 & 0 & 0.0 \\
Total & $\mathbf{9 4 9 4}$ & $\mathbf{1 0 0 . 0}$ \\
\hline
\end{tabular}

The intersection of the genes modulated by romidepsin, AZD5582 and SAHA were the largest among all latency reactivation strategies, since they caused the differential expression of the most genes. Therefore, we conducted further analyses with the 948 genes modulated in common by those three strategies ("intersection list" thereof; Figure 1).

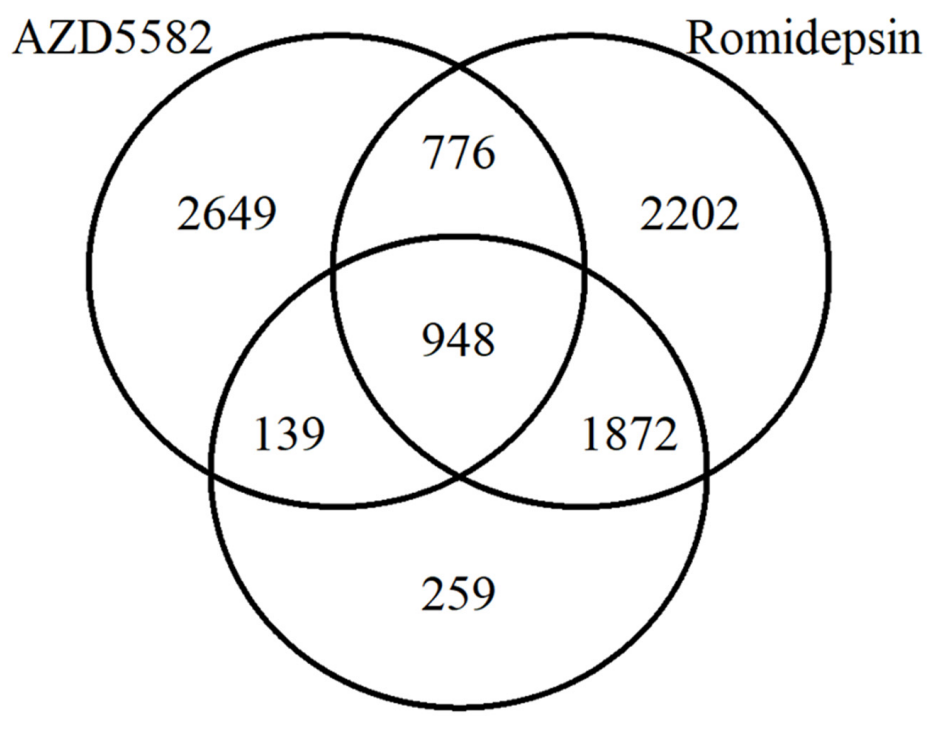

\section{SAHA}

Figure 1. Intersection of differentially expressed genes modulated by romidepsin, SAHA and AZD5582. 
In general, agreements between the intersection list and other studies directly dealing with HIV-1 infection and replication establishment [27-30] were small and within the expected by chance, except for the HIV interaction database [31-33], whose agreement was higher than expected by chance $(p<0.001$, Table 4$)$. We observed that 233 genes of the intersection list $(24.6 \%$ of the intersection list) were already identified in viral-host interaction pathways. Additionally, we detected 110 non-coding RNA genes in the intersection list (11.6\%; 108 belonging to lncRNA class and the remaining two belonging to miRNA or antisense RNA classes).

Table 4. Observed and expected intersection of the genes lists of other studies involving HIV replication and life cycle, alongside HIV Human Interaction Database and RNAcentral, a database of non-coding RNA, with the genes modulated by AZD5582, romidepsin and SAHA list ( $n=948$ genes). The binomial distribution was used to test the null hypothesis that the intersection of the differentially expressed genes and other reported genes is equal or less than expected by chance via one-sided tests. The expected intersection was calculated through simulation studies involving the genome size $(n=28,395$ annotated gene) and the sizes of the two gene lists pairwise compared.

\begin{tabular}{|c|c|c|c|c|}
\hline Reference or Database & $\begin{array}{l}\text { Unique } \\
\text { Genes }\end{array}$ & $\begin{array}{l}\text { Observed } \\
\text { Intersection }\end{array}$ & $\begin{array}{c}\text { Expected } \\
\text { Intersection }\end{array}$ & $p$-Value \\
\hline Konig et al. $2008[28]^{a}$ & 406 & 14 & 13 & 0.43 \\
\hline Zhou et al. 2008 [29] & 264 & 9 & 9 & 0.55 \\
\hline Yeung et al. 2009 [30] & 262 & 11 & 9 & 0.29 \\
\hline HIV-1 Human Interaction Database $[31-33]^{b}$ & 4667 & 233 & 156 & $<0.001$ \\
\hline RNAcentral [34] ${ }^{\mathrm{b}}$ & 7972 & 110 & 266 & 1.00 \\
\hline
\end{tabular}

${ }^{a}$ includes some genes detected by the Brass et al. 2008 study [27], ${ }^{\text {b }}$ Data retrieved as of 13 August 2020.

The GO analysis results (with the intersection list as input) showed that 278 pathways from the biological process ontology were enriched after multiple comparison adjustment by FDR. GO terms related to cell activation (GO:0042110 "T cell activation"; GO:0001775 "cell activation", GO:0002694 "regulation of leukocyte activation"), differentiation (GO:0030154 "cell differentiation"), proliferation (GO:0008283 "cell population proliferation") and cell signaling (GO:0023052 "signaling"; GO:0007165 "signal transduction"; GO:0023051 "regulation of signaling") were prevalent among the enriched pathways. Signal transduction pathways were also enriched alongside signaling pathways. with the participation of mitogen-activated protein kinase (MAPK) and Rho-GTPases pathways (GO:0043405 "regulation of MAP kinase activity; GO:0043407 "negative regulation of MAP kinase activity"; GO:0007266 "Rho protein signal transduction"; GO:0035023 "regulation of Rho protein signal transduction"). Select enriched GO terms (sorted by FDR-adjusted p-value) are displayed in Table 5; the complete list is displayed on Table S5. The reactome pathway analysis detected eight enriched pathways in common: R-HSA-8878171 "Transcriptional regulation by RUNX1", R-HSA-3928665 "EPH-ephrin mediated repulsion of cells", R-HSA-416482 “G alpha (12/13) signaling events", R-HSA-194840 “Rho GTPase cycle", R-HSA-8939236 "RUNX1 regulates transcription of genes involved in differentiation of HSCs", R-HSA-157118 "Signaling by NOTCH", R-HSA-194315 "Signaling by Rho GTPases" and R-HSA-195258 “RHO GTPase Effectors" (Table S6). 
Table 5. Partial results from the gene ontology (GO) analysis of differentially expressed genes modulated by AZD5582, romidepsin and SAHA ( $n=948$ genes) identified through reanalysis of gene expression profiles of CD4+ T cells treated with HIV-1 latency reversal agents (top 20 terms among 278 enriched terms, sorted by false discovery rate $p$-value from over-representation test).

\begin{tabular}{|c|c|c|c|}
\hline Pathways and Ranks & GO id & Term & FDR-Adjusted $p$-Value \\
\hline \multicolumn{4}{|l|}{ Cell activation } \\
\hline 33 & GO:0042110 & $\mathrm{T}$ cell activation & $1.03 \times 10^{-8}$ \\
\hline 46 & GO:0001775 & cell activation & $8.97 \times 10^{-8}$ \\
\hline 76 & GO:0002694 & regulation of leukocyte activation & $1.44 \times 10^{-6}$ \\
\hline \multicolumn{4}{|l|}{ Cell differentiation } \\
\hline 16 & GO:0000902 & cell morphogenesis & $2.59 \times 10^{-10}$ \\
\hline 38 & GO:0030154 & cell differentiation & $3.19 \times 10^{-8}$ \\
\hline 94 & GO:0000904 & cell morphogenesis involved in differentiation & $4.35 \times 10^{-6}$ \\
\hline \multicolumn{4}{|l|}{ Cell proliferation } \\
\hline 43 & GO:0032943 & mononuclear cell proliferation & $7.36 \times 10^{-8}$ \\
\hline 112 & GO:0032944 & regulation of mononuclear cell proliferation & $1.02 \times 10^{-5}$ \\
\hline 135 & GO:0008283 & cell population proliferation & $2.54 \times 10^{-5}$ \\
\hline \multicolumn{4}{|l|}{ Cell signaling } \\
\hline 7 & GO:0023052 & signaling & $4.82 \times 10^{-14}$ \\
\hline 12 & GO:0007165 & signal transduction & $9.96 \times 10^{-12}$ \\
\hline 15 & GO:0023051 & regulation of signaling & $1.25 \times 10^{-10}$ \\
\hline \multicolumn{4}{|l|}{ MAPK } \\
\hline 212 & GO:0043405 & regulation of MAP kinase activity & 0.000246 \\
\hline 219 & GO:0043407 & negative regulation of MAP kinase activity & 0.000305 \\
\hline \multicolumn{4}{|l|}{ Rho GTPases } \\
\hline 62 & GO:0007266 & Rho protein signal transduction & $4.87 \times 10^{-7}$ \\
\hline 75 & GO:0035023 & regulation of Rho protein signal transduction & $1.35 \times 10^{-6}$ \\
\hline
\end{tabular}

\section{Discussion}

We searched for studies concerning HIV-1 reactivation experiments which aimed at reservoir elimination. We obtained RNA-seq reads from 45 samples of human CD4+ T cells across six studies, realigned to the reference human genome, counted, and normalized expression hits, then obtained lists of DEGs in response to LRA treatment. Our goal was to search for genes that could be used for optimizing HIV-1 reactivation, since there has been slow progress in "shock-and-kill" strategies. Re-analyzing studies with different LRAs could provide clues to common genes modulated during HIV-1 reactivation, therefore new strategies could be sought with these candidates in mind. To this end, we performed a cross-reference with other studies from the literature: genome-wide siRNA screens to identify factors involved with HIV-1 replication and life cycle [27-30], and two databases, HIV-1 Human Protein Interaction Database [17] and RNAcentral [34].

We observed that among the nine LRAs strategies, two (AS1842856 and IL-15) did not significantly modulate gene expression during reanalysis. Three strategies: romidepsin, AZD5582 and SAHA modulated the expression of the most genes across studies. Therefore, we will mostly focus the discussion on them. The other four strategies modulated far less genes when compared to the top three LRAs. This may explain observations that disulfiram was inefficient to reduce the size of HIV-1 reservoir in a single-arm pilot study [53] as well as bryostatin not affecting the transcription of latent HIV-1 in a double-blind phase I pilot clinical-trial [54]. IL-7 use was even associated with transient expansion of HIV-1 reservoir in two independent studies [55,56]. However, it is important to highlight that modulating more genes does not necessarily translate to more efficiency in reservoir reactivation either; indeed it could lead to generalized toxicity or activation of the immune system due to activation of several "off-target" genes [44].

Romidepsin is a histone deacetylase inhibitor that was already investigated in latency reactivation clinical trials. In a small single-arm protocol, romidepsin administration was safe and induced HIV-1 transcription resulting in detectable plasma HIV-1 RNA in patients with long-term viral suppression [57]. 
Indeed, our results seem to provide a mechanistic evidence for this efficiency, since romidepsin activated the most genes across the studies included in the reanalysis, which would favor HIV-1 reemergence among latently infected $\mathrm{T}$ cells. In a following phase $1 \mathrm{~B} / 2 \mathrm{~A}$ protocol, the combination of romidepsin and an experimental HIV-1 vaccine resulted in a 38\% reduction in the size of the HIV-1 reservoir from baseline to eight weeks after treatment administration, but it did not seem to prolong median time to virus rebound during ART interruption, meaning that further optimizations in the shock-and-kill strategy are necessary before it can translate to clinical practice [58].

The molecule AZD5582 was tested in macaque and humanized mice alongside ex vivo CD4+ T cells. It robustly reactivated HIV-1 and simian immunodeficiency virus SIV latency from resting CD4+ T cells systemically in those animal models. AZD5582 efficiently inhibits cellular inhibitor of apoptosis protein 1 (cIAP1), a strong repressor of non-canonical NF- $\mathrm{kB}$ [44].

SAHA has lower potency than most other HDACi. SAHA in vitro half maximal inhibitory concentration $\left(\mathrm{IC}_{50}\right)$ is on the micromolar range, whereas romidepsin $\mathrm{IC}_{50}$ is on the nanomolar range [59]. A previous study compared the HIV-1-reactivation potential of five HDACi (panobinostat, givinostat, belinostat, SAHA and valproic acid) and found that SAHA had potency superior only to valproic acid [60]. This may explain why SAHA modulated less genes, especially in the Mohammadi et al. [40] and Golumbeanu et al. [41] studies, but nonetheless, several were in common with romidepsin.

Beliakova-Bethell et al. [42] stimulated CD4+ T cells with SAHA or romidepsin and compared the modulated genes by these two agents with the HIV-1 Human Protein Interaction Database and obtained a match of 64 genes overall (up- and down-regulated by both SAHA and romidepsin and up- and down-regulated by either of them alone). The genes CDK2, HSPA2, TNF and RCOR2 were up-regulated and the genes IL16, ITK, MX2, NCOA2 and PIK3CG were down-regulated by both romidepsin and SAHA and were present in our intersection list. These genes are HIV-1 activators, except for, IL16, MX2 and PIK3CG which are HIV-1 repressors, as curated by Beliakova-Bethell et al. [42].

The concordance between our results and the genome-wide siRNA screens [27-30] was small, as only 33 unique genes matched our intersection list, within the expected under the binomial test null hypothesis. However, our intersection list had a higher than expected agreement with the HIV-1 Human Interaction Database [31-33] following a binomial distribution. Therefore, we have confidence that our intersection list is representative of the true subset of genes involved in HIV-1 reactivation during treatment with LRAs.

One of the reasons "shock-and-kill" treatments do not work as expected may due to post-transcriptional blocks of HIV-1 reactivation, which limits the de novo production of viral particles [40], hampering the detection by the immune system. The role of non-coding RNAs in cellular post-transcriptional regulation is increasingly being investigated. Several classes of ncRNAs were characterized: lcRNAs and miRNAs the best examples, and they may have an influence in the interplay between HIV-1 and host cellular machinery [61].

For example, the NEAT1 and NRON lncRNAs were associated with HIV-1 latency establishment by in vitro studies [62,63]. Host miRNAs, such as MIR28, MIR125B, MIR150, MIR223, and MIR382 repress HIV-1 mRNAs in resting CD4+ T cells $[64,65]$. Interestingly, NRON was modulated by SAHA and romidepsin, perhaps confirming that the cells treated with those LRAs were indeed in a reactivation/proliferation internal milieu, suppressing the regulation pathways brought upon by these RNA molecules.

Other miRNA with evidence pointing to a role in HIV-1 reactivation was detected by our methodology: MIR155HG. The function of this miRNA is to suppress the expression of TRIM32. HIV-1 trans-activator protein (Tat) sequesters TRIM32 into cytoplasmatic bodies to favor viral expression. Moreover, TRIM32 participates in NF-kB pathway activation. Thus, MIR155HG/MIR155 expression following reactivation by LRAs may in fact antagonize ("backfire") its own process of shock-and-kill [65,66]. Importantly, MIR155HG was activated precisely by AZD5582, which is associated with NF-кB pathway activation. TRIM32 itself was not present in our DEGs list, but other 25 related genes were. TRIM14, for example, was modulated by romidepsin, SAHA and AZD5582. 
Moreover, we observed that SAHA up-regulated the expression of TCF4, the gene of a downstream effector of the Wnt/ $\beta$-catenin pathway that represses both basal and Tat-mediated HIV-1 transcription in astrocytes [67], perhaps by sequestering Tat in the cytoplasm [68,69]. This means that LRAs also "backfire" by up-regulating Wnt pathways in a similar manner to NF- $\mathrm{B}$ pathway activation as discussed above. Notch and Wnt pathways are interconnected in some cellular processes, with Notch being associated with T cell survival and quiescence [70], unfavorable outcomes in the shock-and-kill concept.

The MAPK signaling pathway is exploited by HIV-1 to activate its transcription via translocation of $\mathrm{NF}-\kappa \mathrm{B}$ to the nucleus and increase in the synthesis of positive transcription elongation factor $\mathrm{b}(\mathrm{P}-\mathrm{TEFb})$, a key player in HIV-1 genome transcriptional elongation [71]. However, MAPK pathways may protect $\beta$-catenin by inhibiting the glycogen synthase kinase $3 \beta$ (GSK3 $\beta$ ) enzyme, which degrades the former in the cytoplasm [69]. We identified enrichment in certain MAPK pathways. Incidentally, MAPK pathways crosstalk with the extracellular-signal-regulated kinase (ERK) pathway. Evidence show that HIV-1 promotes sustained activation of MAPK pathways; this in turn elicits a strong, transient ERK activation, which leads to expression of TNF- $\alpha$ which leads to inflammation and FasL up-regulation, which leads to apoptosis, a desirable outcome for "shock-and-kill" strategy. However, it also may lead to the expression of PD-1, a marker of T cell exhaustion [72], which is undesirable since it suppress T cell cytotoxicity against infected/HIV-1-reactivated cells [73].

RUNX1 and related genes were modulated by romidepsin (RUNX1-IT1 and RUNX2) and AZD5582 (RUNX1-IT1). The RUNX1 protein is a member of a transcription factor family that binds the cofactor CBF- $\beta$, to form a transcription factor complex involved in hematopoiesis and CD4+ T cell differentiation. An in vitro study suggests that RUNX1 is involved in HIV-1 latency establishment and a treatment with a RUNX1 inhibitor can reverse the latency [74].

HIV-1 proteins can promote changes in the actin organization, the most abundant cell protein and major constituent of the cytoskeleton. They up-regulate actin regulators gene expression or indirectly activate them. For example, HIV-1 can manipulate Rho-GTPases, a family of proteins that regulate processes of cell morphology change and migration [75]. Interestingly, our reanalysis detected the up-regulation of genes associated with Rac1 and Cdc42 enzymes, major regulators of the cytoskeleton dynamics [75,76] (especially CDC42EP2, activated by romidepsin, SAHA and AZD5582 in parallel).

We recognize some limitations our study. First, the data are coming from studies with different sources of cells (from long-term treated patients [40,43,44] or infected in vitro [41,42]). Thus, effects coming from differences in the clonality of the reservoir exposure to antiretroviral drugs, may possibly bias gene expression profiles. Second, the process of HIV-1 latency establishment and its reactivation are highly stochastic phenomena. It is possible that the LRAs only activating a fraction of the cells, which could also introduce bias into RNA expression profiles [77,78].

However, we believe that our cross-referencing helped gauge the relative contribution of each LRA in the patterns of gene modulation and correct (at least some part of) the bias introduced. Second, and we share this limitation with every study of gene expression, is that modulation of transcription does not perfectly correlates with protein abundance, due to the cellular post-transcriptional and translational/post-translational regulatory processes [79]. Therefore, we tried to not become too speculative about the results. Thus, we selected pathways to present in the discussion that already have recognized roles in HIV replication and life cycle, to be as close to a biological significance as possible.

\section{Conclusions}

The methodology of RNA-Seq contributed to increased gene pathway discovery pertaining to major cellular processes, including HIV-1 infection, life cycle and reactivation. Latency reversal is one of the most sought-after method for a functional cure of HIV-1 infection, as ART is incapable of eradicate the virus from the organism of those infected. In our study, we performed a reanalysis of latency reversal strategies and provided a catalog of genes modulated by several LRAs. Although the overlap between the genes modulated by each LRA may seem small, it could help future "shock-and-kill" strategies due to a more profound knowledge of gene pathways involved. Indeed, we could identify 
common pathways with already observed roles in HIV-1 replication (about 230 genes curated in a specialized database), about 100 non-coding RNA genes among the genes and linked them to the three most prolific LRAs (AZD5582, romidepsin and SAHA), in quantitative terms (number of modulated genes). Therefore, we have confidence that our reanalysis truly reflected biologically significant genes in the context of HIV-1 reactivation.

Supplementary Materials: The following are available online at http://www.mdpi.com/2076-2607/8/10/1505/s1, Table S1: Detailed sample list of the studies included in the reanalysis of gene expression profiles of CD4+ T cells treated with HIV-1 latency reversal agents, Table S2: Results of differential gene expression analysis by negative binomial generalized linear models with testing by quasi-likelihood F-test, per gene, per latency reversal agent (LRA), Table S3: Detailed cross-reference of individual studies DEGs (9494 unique genes) and other studies involving HIV replication and life cycle, alongside HIV Human Interaction Database and RNAcentral, a database of non-coding RNA, Table S4: Detailed distribution of how many genes were activated by number of HIV latency reversal agents ( $n=7$ strategies), Table S5: Gene ontology (GO) analysis results. The 948 genes modulated by AZD5582, romidepsin and SAHA were used as input, Table S6: Reactome pathway analysis results displaying enriched pathways by AZD5582, romidepsin and SAHA.

Author Contributions: Conceptualization, A.V.C.C.; methodology, A.V.C.C. and R.R.d.M.; software, A.V.C.C. and R.R.d.M.; validation, A.V.C.C.; formal analysis, A.V.C.C.; investigation, A.V.C.C. and S.C.; resources, S.C.; data curation, A.V.C.C.; writing—original draft preparation, A.V.C.C.; writing—review and editing, R.R.d.M. and S.C.; visualization, A.V.C.C.; supervision, S.C.; project administration, S.C.; funding acquisition, S.C. All authors have read and agreed to the published version of the manuscript.

Funding: This research was funded by the following research programs: ISE-EMH(Italian-Slovenian Ecosystem for Electronic and Mobile Health) from European Community (grant number: 07/2019); BioHub - A High-throughput Platform For OMICs Data Analysis and Integration from the Italian Ministry of Health (grant number: RC03/20); Brazilian National Research Council (CNPq), grant number APQ 405825-2018-8.

Conflicts of Interest: The authors declare no conflict of interest.

\section{References}

1. Barre-Sinoussi, F.; Chermann, J.; Rey, F.; Nugeyre, M.; Chamaret, S.; Gruest, J.; Dauguet, C.; Axler-Blin, C.; Vezinet-Brun, F.; Rouzioux, C.; et al. Isolation of a T-lymphotropic retrovirus from a patient at risk for acquired immune deficiency syndrome (AIDS). Science 1983, 220, 868-871. [CrossRef] [PubMed]

2. Gallo, R.C.; Sarin, P.S.; Gelmann, E.P.; Robert-Guroff, M.; Richardson, E.; Kalyanaraman, V.S.; Mann, D.; Sidhu, G.D.; Stahl, R.E.; Zolla-Pazner, S.; et al. Isolation of human T-cell leukemia virus in acquired immune deficiency syndrome (AIDS). Science 1983, 220, 865-867. [CrossRef] [PubMed]

3. Sleasman, J.W.; Goodenow, M.M. 13. HIV-1 infection. J. Allergy Clin. Immunol. 2003, 111, S582-S592. [CrossRef]

4. Bartlett, J.A.; DeMasi, R.; Quinn, J.; Moxham, C.; Rousseau, F. Overview of the effectiveness of triple combination therapy in antiretroviral-naive HIV-1 infected adults. AIDS 2001, 15, 1369-1377. [CrossRef] [PubMed]

5. Abrahams, M.R.; Joseph, S.B.; Garrett, N.; Tyers, L.; Moeser, M.; Archin, N.; Council, O.D.; Matten, D.; Zhou, S.; Doolabh, D.; et al. The replication-competent HIV-1 latent reservoir is primarily established near the time of therapy initiation. Sci. Transl. Med. 2019, 11. [CrossRef]

6. Zhang, J.; Crumpacker, C. Eradication of HIV and Cure of AIDS, Now and How? Front. Immunol. 2013, 4, 337. [CrossRef]

7. Siliciano, J.D.; Kajdas, J.; Finzi, D.; Quinn, T.C.; Chadwick, K.; Margolick, J.B.; Kovacs, C.; Gange, S.J.; Siliciano, R.F. Long-term follow-up studies confirm the stability of the latent reservoir for HIV-1 in resting CD4+ T cells. Nat. Med. 2003, 9, 727-728. [CrossRef]

8. Hütter, G.; Nowak, D.; Mossner, M.; Ganepola, S.; Müßig, A.; Allers, K.; Schneider, T.; Hofmann, J.; Kücherer, C.; Blau, O.; et al. Long-Term Control of HIV by CCR5 Delta32/Delta32 Stem-Cell Transplantation. N. Engl. J. Med. 2009, 360, 692-698. [CrossRef]

9. Gupta, R.K.; Peppa, D.; Hill, A.L.; Galvez, C.; Salgado, M.; Pace, M.; McCoy, L.E.; Griffith, S.A.; Thornhill, J.; Alrubayyi, A.; et al. Evidence for HIV-1 cure after CCR5Delta32/Delta32 allogeneic haemopoietic stem-cell transplantation 30 months post analytical treatment interruption: A case report. Lancet HIV 2020. [CrossRef]

10. Sengupta, S.; Siliciano, R.F. Targeting the Latent Reservoir for HIV-1. Immunity 2018, 48, 872-895. [CrossRef] 
11. Wang, Z.; Gerstein, M.; Snyder, M. RNA-Seq: A revolutionary tool for transcriptomics. Nat. Rev. Genet. 2009, 10, 57-63. [CrossRef] [PubMed]

12. Costa-Silva, J.; Domingues, D.; Lopes, F.M. RNA-Seq differential expression analysis: An extended review and a software tool. PLoS ONE 2017, 12, e0190152. [CrossRef] [PubMed]

13. Wang, B.; Kumar, V.; Olson, A.; Ware, D. Reviving the Transcriptome Studies: An Insight Into the Emergence of Single-Molecule Transcriptome Sequencing. Front. Genet. 2019, 10, 384. [CrossRef] [PubMed]

14. Leinonen, R.; Sugawara, H.; Shumway, M.; International Nucleotide Sequence Database, C. The sequence read archive. Nucleic Acids Res. 2011, 39, D19-D21. [CrossRef] [PubMed]

15. Barrett, T.; Wilhite, S.E.; Ledoux, P.; Evangelista, C.; Kim, I.F.; Tomashevsky, M.; Marshall, K.A.; Phillippy, K.H.; Sherman, P.M.; Holko, M.; et al. NCBI GEO: Archive for functional genomics data sets-update. Nucleic Acids Res. 2013, 41, D991-D995. [CrossRef] [PubMed]

16. Edgar, R.; Domrachev, M.; Lash, A.E. Gene Expression Omnibus: NCBI gene expression and hybridization array data repository. Nucleic Acids Res. 2002, 30, 207-210. [CrossRef]

17. NCBI Resource Coordinators. Database resources of the National Center for Biotechnology Information. Nucleic Acids Res. 2018, 46, D8-D13. [CrossRef]

18. Sadowski, I.; Hashemi, F.B. Strategies to eradicate HIV from infected patients: Elimination of latent provirus reservoirs. Cell. Mol. Life Sci. 2019, 76, 3583-3600. [CrossRef]

19. Zhu, Y.; Stephens, R.M.; Meltzer, P.S.; Davis, S.R. SRAdb: Query and use public next-generation sequencing data from within R. BMC Bioinform. 2013, 14, 19. [CrossRef]

20. R Core Team. R: A Language and Environment for Statistical Computing. Available online: http: //www.r-project.org/ (accessed on 3 July 2019).

21. Bolger, A.M.; Lohse, M.; Usadel, B. Trimmomatic: A flexible trimmer for Illumina sequence data. Bioinformatics 2014, 30, 2114-2120. [CrossRef]

22. Dobin, A.; Davis, C.A.; Schlesinger, F.; Drenkow, J.; Zaleski, C.; Jha, S.; Batut, P.; Chaisson, M.; Gingeras, T.R. STAR: Ultrafast universal RNA-seq aligner. Bioinformatics 2013, 29, 15-21. [CrossRef] [PubMed]

23. Liao, Y.; Smyth, G.K.; Shi, W. The R package Rsubread is easier, faster, cheaper and better for alignment and quantification of RNA sequencing reads. Nucleic Acids Res 2019, 47, e47. [CrossRef] [PubMed]

24. Robinson, M.D.; McCarthy, D.J.; Smyth, G.K. edgeR: A Bioconductor package for differential expression analysis of digital gene expression data. Bioinformatics 2010, 26, 139-140. [CrossRef]

25. Gentleman, R. Annotate: Annotation for Microarrays. R Package Version 1.62.0.; Springer: New York, NY, USA, 2019.

26. Carlson, M. Org.Hs.eg.db: Genome Wide Annotation for Human. R Package Version 3.8.2.; Springer: New York, NY, USA, 2019.

27. Brass, A.L.; Dykxhoorn, D.M.; Benita, Y.; Yan, N.; Engelman, A.; Xavier, R.J.; Lieberman, J.; Elledge, S.J. Identification of host proteins required for HIV infection through a functional genomic screen. Science 2008, 319, 921-926. [CrossRef]

28. Konig, R.; Zhou, Y.; Elleder, D.; Diamond, T.L.; Bonamy, G.M.; Irelan, J.T.; Chiang, C.Y.; Tu, B.P.; De Jesus, P.D.; Lilley, C.E.; et al. Global analysis of host-pathogen interactions that regulate early-stage HIV-1 replication. Cell 2008, 135, 49-60. [CrossRef] [PubMed]

29. Zhou, H.; Xu, M.; Huang, Q.; Gates, A.T.; Zhang, X.D.; Castle, J.C.; Stec, E.; Ferrer, M.; Strulovici, B.; Hazuda, D.J.; et al. Genome-scale RNAi screen for host factors required for HIV replication. Cell Host Microbe 2008, 4, 495-504. [CrossRef]

30. Yeung, M.L.; Houzet, L.; Yedavalli, V.S.; Jeang, K.T. A genome-wide short hairpin RNA screening of jurkat T-cells for human proteins contributing to productive HIV-1 replication. J. Biol. Chem. 2009, 284, 19463-19473. [CrossRef]

31. Ptak, R.G.; Fu, W.; Sanders-Beer, B.E.; Dickerson, J.E.; Pinney, J.W.; Robertson, D.L.; Rozanov, M.N.; Katz, K.S.; Maglott, D.R.; Pruitt, K.D.; et al. Cataloguing the HIV type 1 human protein interaction network. Aids Res. Hum. Retrovir. 2008, 24, 1497-1502. [CrossRef]

32. Fu, W.; Sanders-Beer, B.E.; Katz, K.S.; Maglott, D.R.; Pruitt, K.D.; Ptak, R.G. Human immunodeficiency virus type 1, human protein interaction database at NCBI. Nucleic Acids Res. 2009, 37, D417-D422. [CrossRef]

33. Pinney, J.W.; Dickerson, J.E.; Fu, W.; Sanders-Beer, B.E.; Ptak, R.G.; Robertson, D.L. HIV-host interactions: A map of viral perturbation of the host system. AIDS 2009, 23, 549-554. [CrossRef]

34. The RNAcentral Consortium. RNAcentral: A hub of information for non-coding RNA sequences. Nucleic Acids Res. 2019, 47, D221-D229. [CrossRef] [PubMed] 
35. O'Leary, N.A.; Wright, M.W.; Brister, J.R.; Ciufo, S.; Haddad, D.; McVeigh, R.; Rajput, B.; Robbertse, B.; Smith-White, B.; Ako-Adjei, D.; et al. Reference sequence (RefSeq) database at NCBI: Current status, taxonomic expansion, and functional annotation. Nucleic Acids Res. 2016, 44, D733-D745. [CrossRef] [PubMed]

36. Chen, H.; Boutros, P.C. VennDiagram: A package for the generation of highly-customizable Venn and Euler diagrams in R. BMC Bioinform. 2011, 12, 35. [CrossRef]

37. FitzJohn, R. Ids: Generate Random Identifiers. R Package Version 1.0.1.; Springer: New York, NY, USA, 2017.

38. Ritchie, M.E.; Phipson, B.; Wu, D.; Hu, Y.; Law, C.W.; Shi, W.; Smyth, G.K. limma powers differential expression analyses for RNA-sequencing and microarray studies. Nucleic Acids Res. 2015, 43, e47. [CrossRef] [PubMed]

39. Yu, G.; He, Q.Y. ReactomePA: An R/Bioconductor package for reactome pathway analysis and visualization. Mol. Biosyst. 2016, 12, 477-479. [CrossRef]

40. Mohammadi, P.; di Iulio, J.; Munoz, M.; Martinez, R.; Bartha, I.; Cavassini, M.; Thorball, C.; Fellay, J.; Beerenwinkel, N.; Ciuffi, A.; et al. Dynamics of HIV latency and reactivation in a primary CD4+ T cell model. PLoS Pathog. 2014, 10, e1004156. [CrossRef]

41. Golumbeanu, M.; Cristinelli, S.; Rato, S.; Munoz, M.; Cavassini, M.; Beerenwinkel, N.; Ciuffi, A. Single-Cell RNA-Seq Reveals Transcriptional Heterogeneity in Latent and Reactivated HIV-Infected Cells. Cell Rep. 2018, 23, 942-950. [CrossRef]

42. Beliakova-Bethell, N.; Mukim, A.; White, C.H.; Deshmukh, S.; Abewe, H.; Richman, D.D.; Spina, C.A. Histone deacetylase inhibitors induce complex host responses that contribute to differential potencies of these compounds in HIV reactivation. J. Biol. Chem. 2019, 294, 5576-5589. [CrossRef]

43. Kulpa, D.A.; Talla, A.; Brehm, J.H.; Ribeiro, S.P.; Yuan, S.; Bebin-Blackwell, A.-G.; Miller, M.; Barnard, R.; Deeks, S.G.; Hazuda, D.; et al. Differentiation into an Effector Memory Phenotype Potentiates HIV-1 Latency Reversal in CD4 ${ }^{+}$T Cells. J. Virol. 2019, 93, e00969-19. [CrossRef]

44. Nixon, C.C.; Mavigner, M.; Sampey, G.C.; Brooks, A.D.; Spagnuolo, R.A.; Irlbeck, D.M.; Mattingly, C.; Ho, P.T.; Schoof, N.; Cammon, C.G.; et al. Systemic HIV and SIV latency reversal via non-canonical NF-kappaB signalling in vivo. Nature 2020, 578, 160-165. [CrossRef]

45. Bosque, A.; Nilson, K.A.; Macedo, A.B.; Spivak, A.M.; Archin, N.M.; Van Wagoner, R.M.; Martins, L.J.; Novis, C.L.; Szaniawski, M.A.; Ireland, C.M.; et al. Benzotriazoles Reactivate Latent HIV-1 through Inactivation of STAT5 SUMOylation. Cell Rep. 2017, 18, 1324-1334. [CrossRef]

46. White, C.H.; Beliakova-Bethell, N.; Lada, S.M.; Breen, M.S.; Hurst, T.P.; Spina, C.A.; Richman, D.D.; Frater, J.; Magiorkinis, G.; Woelk, C.H. Transcriptional Modulation of Human Endogenous Retroviruses in Primary CD4+ T Cells Following Vorinostat Treatment. Front. Immunol. 2018, 9, 603. [CrossRef] [PubMed]

47. Trypsteen, W.; White, C.H.; Mukim, A.; Spina, C.A.; De Spiegelaere, W.; Lefever, S.; Planelles, V.; Bosque, A.; Woelk, C.H.; Vandekerckhove, L.; et al. Long non-coding RNAs and latent HIV-A search for novel targets for latency reversal. PLoS ONE 2019, 14, e0224879. [CrossRef] [PubMed]

48. Vemula, S.V.; Maxwell, J.W.; Nefedov, A.; Wan, B.L.; Steve, J.; Newhard, W.; Sanchez, R.I.; Tellers, D.; Barnard, R.J.; Blair, W.; et al. Identification of proximal biomarkers of PKC agonism and evaluation of their role in HIV reactivation. Antivir. Res. 2017, 139, 161-170. [CrossRef]

49. Spina, C.A.; Anderson, J.; Archin, N.M.; Bosque, A.; Chan, J.; Famiglietti, M.; Greene, W.C.; Kashuba, A.; Lewin, S.R.; Margolis, D.M.; et al. An in-depth comparison of latent HIV-1 reactivation in multiple cell model systems and resting CD4+ T cells from aviremic patients. PLoS Pathog. 2013, 9, e1003834. [CrossRef] [PubMed]

50. Pandey, A.; Kumar, G.S.; Kadakol, A.; Malek, V.; Gaikwad, A.B. FoxO1 Inhibitors: The Future Medicine for Metabolic Disorders? Curr. Diabetes Rev. 2016, 12, 223-230. [CrossRef]

51. Hennessy, E.J.; Adam, A.; Aquila, B.M.; Castriotta, L.M.; Cook, D.; Hattersley, M.; Hird, A.W.; Huntington, C.; Kamhi, V.M.; Laing, N.M.; et al. Discovery of a novel class of dimeric Smac mimetics as potent IAP antagonists resulting in a clinical candidate for the treatment of cancer (AZD5582). J. Med. Chem. 2013, 56, 9897-9919. [CrossRef]

52. Kwaa, A.K.; Goldsborough, K.; Walker-Sperling, V.E.; Pianowski, L.F.; Gama, L.; Blankson, J.N. The effect of Ingenol-B on the suppressive capacity of elite suppressor HIV-specific CD8+ T cells. PLoS ONE 2017, 12, e0174516. [CrossRef] 
53. Spivak, A.M.; Andrade, A.; Eisele, E.; Hoh, R.; Bacchetti, P.; Bumpus, N.N.; Emad, F.; Buckheit, R., 3rd; McCance-Katz, E.F.; Lai, J.; et al. A pilot study assessing the safety and latency-reversing activity of disulfiram in HIV-1-infected adults on antiretroviral therapy. Clin. Infect. Dis. Off. Publ. Infect. Dis. Soc. Am. 2014, 58, 883-890. [CrossRef]

54. Gutierrez, C.; Serrano-Villar, S.; Madrid-Elena, N.; Perez-Elias, M.J.; Martin, M.E.; Barbas, C.; Ruiperez, J.; Munoz, E.; Munoz-Fernandez, M.A.; Castor, T.; et al. Bryostatin-1 for latent virus reactivation in HIV-infected patients on antiretroviral therapy. AIDS 2016, 30, 1385-1392. [CrossRef]

55. Katlama, C.; Lambert-Niclot, S.; Assoumou, L.; Papagno, L.; Lecardonnel, F.; Zoorob, R.; Tambussi, G.; Clotet, B.; Youle, M.; Achenbach, C.J.; et al. Treatment intensification followed by interleukin-7 reactivates HIV without reducing total HIV DNA: A randomized trial. AIDS 2016, 30, 221-230. [CrossRef]

56. Logerot, S.; Rancez, M.; Charmeteau-de Muylder, B.; Figueiredo-Morgado, S.; Rozlan, S.; Tambussi, G.; Beq, S.; Couedel-Courteille, A.; Cheynier, R. HIV reservoir dynamics in HAART-treated poor immunological responder patients under IL-7 therapy. AIDS 2018, 32, 715-720. [CrossRef]

57. Sogaard, O.S.; Graversen, M.E.; Leth, S.; Olesen, R.; Brinkmann, C.R.; Nissen, S.K.; Kjaer, A.S.; Schleimann, M.H.; Denton, P.W.; Hey-Cunningham, W.J.; et al. The Depsipeptide Romidepsin Reverses HIV-1 Latency In Vivo. PLoS Pathog. 2015, 11, e1005142. [CrossRef]

58. Leth, S.; Schleimann, M.H.; Nissen, S.K.; Hojen, J.F.; Olesen, R.; Graversen, M.E.; Jorgensen, S.; Kjaer, A.S.; Denton, P.W.; Mork, A.; et al. Combined effect of Vacc-4x, recombinant human granulocyte macrophage colony-stimulating factor vaccination, and romidepsin on the HIV-1 reservoir (REDUC): A single-arm, phase 1B/2A trial. Lancet HIV 2016, 3, e463-e472. [CrossRef]

59. Zain, J.; Kaminetzky, D.; O'Connor, O.A. Emerging role of epigenetic therapies in cutaneous T-cell lymphomas. Expert. Rev. Hematol. 2010, 3, 187-203. [CrossRef]

60. Rasmussen, T.A.; Schmeltz Sogaard, O.; Brinkmann, C.; Wightman, F.; Lewin, S.R.; Melchjorsen, J.; Dinarello, C.; Ostergaard, L.; Tolstrup, M. Comparison of HDAC inhibitors in clinical development: Effect on HIV production in latently infected cells and T-cell activation. Hum. Vaccin. Immunother. 2013, 9 , 993-1001. [CrossRef]

61. Lazar, D.C.; Morris, K.V.; Saayman, S.M. The emerging role of long non-coding RNAs in HIV infection. Virus Res. 2016, 212, 114-126. [CrossRef]

62. Zhang, Q.; Chen, C.Y.; Yedavalli, V.S.; Jeang, K.T. NEAT1 long noncoding RNA and paraspeckle bodies modulate HIV-1 posttranscriptional expression. mBio 2013, 4, e00596-e00612. [CrossRef]

63. Imam, H.; Bano, A.S.; Patel, P.; Holla, P.; Jameel, S. The lncRNA NRON modulates HIV-1 replication in a NFAT-dependent manner and is differentially regulated by early and late viral proteins. Sci. Rep. 2015, 5, 8639. [CrossRef]

64. Huang, J.; Wang, F.; Argyris, E.; Chen, K.; Liang, Z.; Tian, H.; Huang, W.; Squires, K.; Verlinghieri, G.; Zhang, H. Cellular microRNAs contribute to HIV-1 latency in resting primary CD4+ T lymphocytes. Nat. Med. 2007, 13, 1241-1247. [CrossRef]

65. Khoury, G.; Darcis, G.; Lee, M.Y.; Bouchat, S.; Van Driessche, B.; Purcell, D.F.J.; Van Lint, C. The Molecular Biology of HIV Latency. Adv. Exp. Med. Biol. 2018, 1075, 187-212. [PubMed]

66. Ruelas, D.S.; Chan, J.K.; Oh, E.; Heidersbach, A.J.; Hebbeler, A.M.; Chavez, L.; Verdin, E.; Rape, M.; Greene, W.C. MicroRNA-155 Reinforces HIV Latency. J. Biol. Chem. 2015, 290, 13736-13748. [CrossRef] [PubMed]

67. Wortman, B.; Darbinian, N.; Sawaya, B.E.; Khalili, K.; Amini, S. Evidence for regulation of long terminal repeat transcription by Wnt transcription factor TCF-4 in human astrocytic cells. J. Virol. 2002, 76, 11159-11165. [CrossRef] [PubMed]

68. Rossi, A.; Mukerjee, R.; Ferrante, P.; Khalili, K.; Amini, S.; Sawaya, B.E. Human immunodeficiency virus type 1 Tat prevents dephosphorylation of Sp1 by TCF-4 in astrocytes. J. Gen. Virol. 2006, 87, 1613-1623. [CrossRef]

69. Henderson, L.J.; Al-Harthi, L. Role of beta-catenin/TCF-4 signaling in HIV replication and pathogenesis: Insights to informing novel anti-HIV molecular therapeutics. J. Neuroimmune Pharm. 2011, 6, 247-259. [CrossRef]

70. Kulpa, D.A.; Brehm, J.H.; Fromentin, R.; Cooper, A.; Cooper, C.; Ahlers, J.; Chomont, N.; Sekaly, R.P. The immunological synapse: The gateway to the HIV reservoir. Immunol. Rev. 2013, 254, 305-325. [CrossRef]

71. Cary, D.C.; Fujinaga, K.; Peterlin, B.M. Molecular mechanisms of HIV latency. J. Clin. Investig. 2016, 126, 448-454. [CrossRef] 
72. Furler, R.L.; Uittenbogaart, C.H. Signaling through the P38 and ERK pathways: A common link between HIV replication and the immune response. Immunol. Res. 2010, 48, 99-109. [CrossRef]

73. Kim, Y.; Anderson, J.L.; Lewin, S.R. Getting the "Kill" into "Shock and Kill": Strategies to Eliminate Latent HIV. Cell Host Microbe 2018, 23, 14-26. [CrossRef]

74. Klase, Z.; Yedavalli, V.S.; Houzet, L.; Perkins, M.; Maldarelli, F.; Brenchley, J.; Strebel, K.; Liu, P.; Jeang, K.T. Activation of HIV-1 from latent infection via synergy of RUNX1 inhibitor Ro5-3335 and SAHA. PLoS Pathog. 2014, 10, e1003997. [CrossRef]

75. Ospina Stella, A.; Turville, S. All-Round Manipulation of the Actin Cytoskeleton by HIV. Viruses 2018, 10. [CrossRef] [PubMed]

76. Murali, A.; Rajalingam, K. Small Rho GTPases in the control of cell shape and mobility. Cell. Mol. Life Sci. 2014, 71, 1703-1721. [CrossRef] [PubMed]

77. Hansen, M.M.K.; Martin, B.; Weinberger, L.S. HIV Latency: Stochastic across Multiple Scales. Cell Host Microbe 2019, 26, 703-705. [CrossRef]

78. Hataye, J.M.; Casazza, J.P.; Best, K.; Liang, C.J.; Immonen, T.T.; Ambrozak, D.R.; Darko, S.; Henry, A.R.; Laboune, F.; Maldarelli, F.; et al. Principles Governing Establishment versus Collapse of HIV-1 Cellular Spread. Cell Host Microbe 2019, 26, 748-763.e720. [CrossRef]

79. Vogel, C.; Marcotte, E.M. Insights into the regulation of protein abundance from proteomic and transcriptomic analyses. Nat. Rev. Genet. 2012, 13, 227-232. [CrossRef] [PubMed]

(C) 2020 by the authors. Licensee MDPI, Basel, Switzerland. This article is an open access article distributed under the terms and conditions of the Creative Commons Attribution (CC BY) license (http://creativecommons.org/licenses/by/4.0/). 